\title{
Evolución de pacientes sin función renal residual en diálisis peritoneal
}

\author{
Isabel Montesinos Navarro, Nemesio Manuel Martínez Martínez, Cristina Pérez Jiménez, Gonzalo Martínez \\ Fernández, Lourdes de la Vara Iniesta, Juan Pérez Martínez
}

\section{Servicio de Nefrología. Complejo Hospitalario Universitario. Albacete}

\section{Introducción:}

Mantener la función renal residual (FRR) en Diálisis Peritoneal (DP) contribuye a una mejor eliminación de toxinas urémicas y facilita la euvolemia, asociándose además a mejoría de la anemia, del metabolismo mineral-óseo, del estado nutricional e inflamatorio, menor tasa de peritonitis y mayor supervivencia. En nuestra Unidad, algunos pacientes realizan DP sin FRR. Objetivo: valorar los pacientes anúricos de nuestra Unidad, tras un año sin FRR.

\section{Material y métodos:}

25 pacientes en DP sin FRR (un año): 44\% hombres $/ 56 \%$ mujeres (55,64 años). En DP pese a anuria: $88 \%$ decisión personal, $12 \%$ imposibilidad para otra técnica. Incidentes en DP $28 \%(57,1 \%$ procedían de HD y $42,9 \%$ de trasplante), prevalentes en DP $72 \%$ (tiempo en DP hasta anuria: 39,46 meses). Al año en DP sin FRR realizamos bioimpedancia, PET y analíticas. Medimos: eficacia dialítica, situación volumétrica, estado nutricional, trasporte peritoneal, inflamación, anemia, metabolismo mineral-óseo y peritonitis. Analizamos la pauta de DP empleada durante este año.

\section{Resultados:}

Pauta de diálisis:

- DPA (48\% de los pacientes):

- Volumen medio 17,581.

- Soluciones empleadas. Glucosa al 1,5\%: 52,13\%, glucosa al 2,3\%: $45,03 \%$ e icodextrina: $2,84 \%$.
- DPCA (52\% de los pacientes):

- Volumen medio: 8,3I.

- Soluciones: Glucosa al 1,5\%: 56,73\%, glucosa al $2,3 \%: 43,27 \%$.

Eficacia dialítica media:

- $\mathrm{Kt} / \mathrm{V}$ medio 1,98 (DPCA 1,84, DPA 2,13).

- ClCr medio 55,94 ml/min (DPCA 51,58 ml/min, DPA $60,65 \mathrm{ml} / \mathrm{min}$ ).

Ultrafiltración media:

- 1047,32 cc (DPCA: 939,54 cc, DPA: 1164,08 cc).

Estado de hidratación:

- Sobrehidratación (OH) media: 1,58 I (DPCA 1,42 I, DPA 1,73 I).

- OH/ECW: 9,4\%.

Estado nutricional:

- Albúmina media 3,59 g/dl $(76 \%>3,5 \mathrm{~g} / \mathrm{dl})$.

- LTM/m2 medio por BIS: $14,01 \mathrm{Kg} / \mathrm{m} 2$ (76\% de los pacientes en rango).

- E/I medio: 0,93.

Anemia:

- Hba media: $11,62 \mathrm{~g} / \mathrm{dl}$. Hto medio: $35,96 \%$.

- Pacientes con EP0: 80\%. .

- Dosis media de EP0:64,8 mcg/mes.

Inflamación:

- PCR media: 4,76mg/L.

- Metalismo óseo y mineral:

- Fósforo medio $4,47 \mathrm{mg} / \mathrm{dl}$.

- Ca 8,94 mg/dl.

- PTH 173,12 pg/ml. 
Peritonitis:

- 0,44 episodio/paciente/año.

\section{Conclusión:}

Obtenemos adecuada eficacia dialítica de acuerdo a las recomendaciones de las guías. Conseguimos ultrafiltración adecuada, confirmándose correcta situación volumétrica mediante bioimpedancia. Empleamos soluciones al 2,3\%G, aunque en menor cantidad que al 1,5\%G. Empleo de icodextrina anecdótico. Eficacia dialítica y volemia adecuada Anemia, metabolismo mineral-óseo, marcadores inflamatorios y tasa de peritonitis dentro de las recomendaciones. La mayoría de pacientes que continúan en DP sin FRR lo hacen por decisión personal. 